\title{
Cummings’ l(a Under the Perspective of Post-structuralism
}

\author{
LIU Juan \\ Leshan Normal University, Sichuan, China
}

\begin{abstract}
Starting with traditional readings of one of E. E. Cummings' representative poems $l(a$ and then focusing on the post-structural illustration of the poem, this essay gives a thorough analysis of Cummings' experimentation with form and language. It exposes the significance of his innovative writing and proves Cummings' important status in the history of modernist poetry.
\end{abstract}

Keywords: E. E. Cummings, post-structuralism, modern innovative

\section{Introduction}

When it comes to the modern poets of the 20th century, perhaps most people would like to divide them into two groups. Some poets present themselves thoughtful, serious, and eager to claim authority and accept responsibility. Others are determined to remain playful, provocative, in love with games and experiments, and defiant of convention in language as in life. E. E. Cummings's experimentation with form and language places him among the most innovative of 20th century poets. He wrote many poems with unconventional punctuation and capitalization, and unusual line, word, and even letter placements. Even readers who seldom read poetry recognize the distinctive shape that a Cummings' poem makes on the page.

In this essay, the author will adopt post-structuralism to illustrate one of Cummings' representative poems to expose his "new" facets of work and thus to expose the significance of his creative writing. This analysis shall start with critically accepted interpretations of the poem, taken from established critical positions regarding Cummings. It shall then move on to read Cummings in "new" ways, taking the post-structuralist theories of Jacques Derrida as a working basis. The expose of "new" areas in Cummings criticism and his relevance to today's critical thinking will lead to a call for a re-evaluation of Cummings' status in the history of modernist poetry.

\section{Form}

In moving on to the discussion of the poem, we shall investigate claims that Cummings' experimental work, like Mallarmé's, provokes a crisis in language by showing the unstable and undecidable relations between meanings, between meaning and form, and between different grammatical categories. Derrida claimed that this crisis is as a result of the "logic of language and not an aberrant distortion of it". Furthermore, that the crisis is both new — "we are still developing critical methods adequate to it” — and very old — as old as Plato and Aristotle (Derrida, Acts 111). The poem under discussion is $l(a$ :

LIU Juan, MA, associate professor, School of Foreign Languages, Leshan Normal University, Sichuan, China. 
$\mathrm{l}(\mathrm{a}$

le

af

fa

ll

s)

one

1

iness

(CP 673)

This haiku-like poem has been described as the "most delicately beautiful literary construct that Cummings ever created" (Kennedy, 1980, p. 463). Consisting of just four words, which the poem splits into two distinct phrases_- "loneliness" and "a leaf falls"- the poem has generated a wide range of critical analysis. It is with this established criticism that we shall begin. The connection between the two phrases seems at first weak. The falling of a leaf is a concrete act, while the word "loneliness" is an abstract concept. However, conventional criticism has made the link. Rushworth Kidder who described the poem as a "brief description of autumn" stated that "the single leaf falling is a metaphor for both physical and spiritual isolation" (1979, pp. 200-201). Barry Marks, in a highly detailed reading, asked the reader to hold the two phrases simultaneously together so that various possibilities emerge. Thus, "Loneliness is like a falling leaf" or "The feeling of loneliness is the feeling a man gets when he watches a single leaf falling". Marks (1964) concluded that "It does not take much ... to ... think of autumn, the end of the growing season, the death of the year" (p. 23). Autumn (fall) and the autumn of a man's life—death is a lonely business. Such speculation is interesting indeed, but to the critics, not the point of the poem — "it [the poem] asks us to look at the printed page” (Marks, 1964, p. 23). The form of the poem does indeed foster an attitude of internalization, of drawing attention to itself as an artifact, a work of art. To begin with, the poem dribbles down the page, at once suggesting the descent of a falling leaf, while also visually resembling the figure "1", or a vertical stroke on a page (Heusser, 1977, pp. 269-270). The reader's progress is slowed down by the shattered syntax, and the reader's eye is forced into a similar movement as that when watching a descending leaf, both finally coming to a rest on the "ground" ("iness" - the longest and last line). We see that the poem is organized into stanzas [end page 38] of alternating lines of 1-3-1-3-1, while the first four lines alternate vowels/consonants, both indicating, perhaps, the twisting motion of the leaf as it falls. The parentheses aid this twisting movement, showing first, descent one way, then another. The downward movement is enhanced by lines 5 ("ll") and 8 ("l"), which can be seen as visually 
enacting the journey. Without even reading the words and using fields of representation perhaps unusual in poetry (the visual in this case), the reader is drawn toward one of the main themes of the poem-that of "one". It is no surprise that this poem was the first poem in Cummings' book 95 Poems and was numbered "I", further impressing the main theme upon the reader. Furthermore, in the original printing of 95 Poems (1958), l(a appeared opposite a blank page - thus at once suggesting the loneliness explicit in the poem-while all other poems except the last appeared in twos. The 23 characters (including the title) seemed lost, overwhelmed by the white space, and one's eyes are automatically drawn to the fragile construction. Metaphorically, then the poem enacts the vastness of space and the smallness of man within that space. This has existential undertones and implicitly suggests another theme of the poem—-that of death (autumn).

\section{Language}

In his 1974 essay "Mallarmé”, Jacques Derrida contended that Mallarmé's writings have usually been associated with semantic richness - the possibilities that language can be used for multiple meanings, references, and allusions. Instead, Derrida [end page 39] reads it as decomposition of linguistic elements, and especially of the word. Taking Mallarmé's Or as an example, Derrida shows how Mallarmé plays on the French word "or", showing it to be two letters, a syllable, and a word. In fact, Derrida suggests it is all three. Indeed, even as a word, "or" is not stable. It can be a noun ("gold”), an adjective ("golden"), and a conjunction ("now”). Also, being proficient in English, Mallarmé knew that "or” could also be a syllable, a word, or letters in English. Concluding that this is not so much semantic richness as semantic indecision, Derrida contends that this arises from the unsettling placing of letters, sounds, and words - in other words from syntax (the location of linguistic elements), not from semantics (meanings). In fact, it upsets and derails meaning. Thus, Derrida's interest is not the semantic richness but the dislocation of content by strategic syntaxing. This dislocation results in a position where truth/meaning is undecidable, and Derrida can conclude that "No more word: the efficacy often comes from one syllable which scatters the word” (1992, p. 125).

From the description of Derrida's theory, we can see quite clearly how Cummings' poem "fits" into this picture. Cummings decomposes the words to produce a series of results that stem clearly from syllables, or indeed from single letters. Moreover, Cummings extends the fields of representation used to interpret the poem beyond semantics. The poem takes in, as we have seen, the visual, numerical, and French language fields of representation. The poem then becomes a poem of "associative meaning"- that is, a poem which forces the reader to go outside the poem for meaning, despite being constantly forced back into the poem. Thus, in l(a, a tension of sorts develops as the reader is pulled both inside and outside the poem. Let us illustrate this point. To begin with, both the visual and verbal elements of the poem fail to allow the reader direct access to the thing itself. This statement seems paradoxical since we have established that the visual/verbal elements support each other to aid meaning. However, when "reading" a poem, the visual is undermined since the reader's concentration is on individual letters/syllables, which the reader is attempting to build into larger structures—words.

Furthermore, as Foucault pointed out,

As soon as [the reader] begins to read, in fact, shape dissipates ... the [poem] never speaks and represents at the same moment. The very thing that is both seen and read is hushed in the vision, hidden in the reading. (Foucault, 1973, p. 26)

The constant motif of "one", hidden in the visual, is lost when reading, yet simultaneously, the "leaf" and the concept "loneliness" are lost when the visual is favored. Thus, the visual/verbal support system breaks 
down quickly, and furthermore, the poem seems to announce its failure to represent the object-concept-theme visually/verbally by drawing attention to its own artificial self, i.e., the fragile structure swamped in white. As Derrida states, "in their literal sense painting and writing are totally incapable of any intuition of the thing itself, since they deal only in copies, and in copies of copies” (1991, p. 176). We have seen already, in our analysis of "in just”, how language fails to convey single, stable, universal truth/meaning [end page 40] since language can "mean" many things simultaneously. The visual suffers the same fate. According to Derrida, the artist has traditionally embodied the power of seeing and making visible (1993, pp. 48-52). However, to Derrida, drawing originates in blindness. The object or model, even if facing the artist, cannot be seen at the same moment as the mark of drawing is made. There is always a gap or delay. The mark relies on memory and when memory is invoked, the present object is ignored: The artist will be blind to it. Furthermore, drawing, like language, is impossible without the play of presence/absence, and this cannot be seen. Thus, the artistic power of seeing and making visible is inhabited by blindness it cannot recognize. Modes of representation, then fail to convey any truth or "transparent window" to the object; indeed, the artistic medium always intervenes between reader/observer and the thing itself. Thus, when imagining the leaf twisting, descending, or coming to rest, the reader will be blind to the letters/syllables on the page. Thus, the modes of representation used in the poem fail to convey truth/meaning to the reader.

Now, to return to the inside/outside dichotomy: The reader is first pulled inside the poem since the visual elements of the poem fail to convey direct access to the thing itself. The reader goes inside the poem-the verbal/semantic - to find meaning. However, because of the decomposition of the words in the poem, the multiple puns, allusions, and meanings, the reader is forced into other systems of signification outside the poem. Thus, the reader looks outward toward fields of French and numerical representation. This oscillation between inside/outside is one of the many undecided issues within the poem. There are also the undecided issues of abstract/concrete, female/male ("la" and "le"), the numerical/verbal, and the visual/verbal. Furthermore, as we have seen, there is a metaphysical dimension to the poem that links "a leaf falls" and the "autumn" years of a person's life. However, this melancholic reading need not apply, for the state of "loneliness" is not necessarily a negative one (Kidder, 1979, p. 201). The poem seems to be dealing with issues far and beyond that of an interpretative meaning. Its undecided status points to this. Cummings is dealing with the problems of representation itself, and that is a major issue currently under debate. Cummings' work then, seems particularly relevant to today's thinking.

\section{Conclusion}

Cummings' work, in using different fields of representation, disrupts conventional thinking about representation. It is as if Cummings were exploring the limits, not just of language, but of the problems of representation in general.

To conclude, Cummings' poem supports Derrida's radical conclusion that since all the words in this poem can be decomposed, there are no more words. It is undeniable that Cummings' achievement deserves acclaim. He established the poem as a visual object (he can be seen, in fact, as a forerunner of concrete poetry); he revealed, by his $\mathrm{x}$-ray probing, the faceted possibilities of the single word; and he promoted sheer playfulness with language. Despite a growing abundance of second-rate imitations, his poems continue to amuse, delight, and provoke. 


\section{References}

Brooks, C., \& Warren, R. P. (2004). Understanding Poetry. Beijing: Foreign Language Teaching and Research Press. Derrida, J. (1991). A Derrida reader: Between the blinds. (P. Kamuf Ed.). Hemel, Hempstead: Harvester Wheatsheaf. Derrida, J. (1992). Acts of literature. (D. Attridge Ed.). London: Routledge.

Derrida, J. (1993). Memoirs of the blind: The self-portrait and other ruins. (P. A. Brault and M. Naas, Trans.). London: University of Chicago Press.

Foucault, M. (1973). Ceci n'est pas une pipe. Montpellier: Fata Morgana,.

Heusser, M. (1997). I Am My Writing: The Poetry of E. E. Cummings. Tubingen: Stauffenburg Verlag.

Kennedy, R. S. (1980). Dreams in the mirror: A biography of E. E. Cummings. New York: Liveright.

Kidder, R. M. (1979). E. E. Cummings: An introduction to the poetry. New York: Columbia University Press.

Marks, B. (1964). E. E. Cummings. New York: Twayne.

Perrine, L. (1987). Sound and sense: An introduction to poetry. Chicago: Harcourt Brace Jovanovich, Inc.

Rosenthal, M. L. (1960). The modern poets: A critical introduction. Beijing: Foreign Language Teaching and Research Press. 